\title{
Preface: Advanced Research on Offshore Structures and Foundation Design: Part 2
}

\section{T. Fazeres-Ferradosa}

CIIMAR - Interdisciplinary Centre of Marine and Environmental Research of the University of Porto, Terminal de Cruzeiros do Porto de Leixões, Avenida General Norton de Matos, Matosinhos, Portugal; FEUP - Faculty of Engineering of the University of Porto, Department of Civil Engineering, rua Dr. Roberto Frias, Porto, Portugal (Orcid:0000-0002-8549-3320)

\section{P. Rosa-Santos}

CIIMAR - Interdisciplinary Centre of Marine and Environmental Research of the University of Porto, Terminal de Cruzeiros do Porto de Leixões, Avenida General Norton de Matos, Matosinhos, Portugal; FEUP - Faculty of Engineering of the University of Porto, Department of Civil Engineering, rua Dr. Roberto Frias, Porto, Portugal

\section{F. Taveira-Pinto}

CIIMAR - Interdisciplinary Centre of Marine and Environmental Research of the University of Porto, Terminal de Cruzeiros do Porto de Leixões,

Avenida General Norton de Matos, Matosinhos, Portugal; FEUP - Faculty of Engineering of the University of Porto, Department of Civil Engineering, rua Dr. Roberto Frias, Porto, Portugal

\section{Pavlou}

Department of Mechanical and Structural Engineering and Materials Science, University of Stavanger, Norway

\section{F-P. Gao}

Key Laboratory for Mechanics in Fluid Solid Coupling Systems, Institute of Mechanics, Chinese Academy of Sciences, Beijing, 100190, China And School of Engineering Science, University of Chinese Academy of Sciences, Beijing, 100049, China

\section{H. Carvalho}

Department of Structural Engineering, Federal Univeristy of Minas Gerais, Belo Horizonte - MG (Orcid:0000-0001-9732-9969)

\section{S. Oliveira-Pinto}

Equinor ASA (formerly designated Statoil), Forusbeen 50, Stavanger, 4035, Norway

\section{Introduction}

Design of offshore structures and foundations remains a paradigm of the uppermost complexity and innovation in the fields of Maritime, Civil, Mechanical and Environmental Engineering, among numerous other professional domains. With increasingly challenging conditions associated to new offshore locations and more ambitious projects, the advanced research on offshore structures and foundation design acquires additional importance as a key element towards a solid development of offshore engineering practice.

The historical track-record in oil and gas offshore engineering coupled with the modern's World needs, in terms of energy consumption and sustainable exploitation of sea-resources, along with the trends in international policies, which focus on increasing the investment in marine renewables, show that offshore structures and foundations' design still presents key knowledge-gaps, which can only be addressed by means of state-of-the-art research and novel breakthroughs. This became evident in the context provided by Fazeres-Ferradosa et al. (2019) and Taveira-Pinto et al. (2020).

Although such challenges might be difficult to overcome, they undoubtedly represent exciting opportunities towards the improvement of the offshore engineering and maritime industry in general. Natural Hazards, Geopolitical events or even the recently faced SARS-CoV-2 Pandemic, which led to Oil barrels trading for May delivery at around -\$4 (Strachan, 2020), act as painful reminders to stakeholders that Advanced
Research is an important part of a more resilient sector, which bets on a driven search for optimised Levelised Costs of Energy and more efficient and sustainable exploitation of the existing resources.

Current reality and globalised demand and supply engineering services deal with a framework of volatile oil prices and a field of marine renewable energy that is yet to reach its full potential. In this context of uncertainty, the Proceedings of the Institution of Civil Engineers - Maritime Engineering have consistently provided a contribution to the development of the field's state-of-the-art, by publishing special issues, practical case studies and novel research in the offshore engineering domains, e.g. in subsea structures and pipeline's design (Fazeres-Ferradosa et al., 2018; Pavlou and Correia, 2019; Gonçalves et al., 2020), statistical description of met-ocean data (Vanem et al., 2019; Hames et al., 2019), novel design applications and new materials (Pavlou, 2019; Fantuzzi, 2020), fatigue and structural response (Mourão et al., 2020), fixed and floating offshore foundations (Fazeres-Ferradosa et al., 2019b, Edesess et al, 2017, 2018; East, 2018) and marine renewable energy (Jiang et al., 2019; Correia et al., 2019).

\section{Themed Issue Advanced Research on Offshore Structures \& Foundation Design: Part 2}

The current themed issue provides the continuity of Advanced Research on Offshore Structures and Foundation - Part 1 presented in Fazeres-Ferradosa et al. (2019), which reviewed several technical challenges of current trends in offshore 
structures' design. While Part 1 focused on novel approaches to treat met-ocean data for design purposes (Vanem et al., 2019) and the application of new materials to offshore structures, pipelines and foundations (Pavlou et al., 2019), Part 2 now focus on the presentation of innovative research in terms of design aspects of these structures and foundations. This Part 2 is also a result of direct output from the International Offshore Structures Design (IOSD) course and its technical sessions, held in the Faculty of Engineering of the University of Porto, in May 2019. The IOSD course series started in 2016 and resulted from the R\&D activities within the Marine Energy Research Group from the Interdisciplinary Centre of Marine and Environmental Research of the University of Porto (CIIMAR), Portugal. The 2019 edition also counted with the partnership of the Hydraulics and Water Resources Institute (IHRH) (Fazeres-Ferradosa et al., 2019).

Through its editions and spin-off events and partnerships, the IOSD has gathered numerous researchers and professionals operating in the offshore oil and gas and marine renewable energy. The technical sessions held by world class experts have been the centre of fruitful learning classes but also of important discussions on advanced and applied research to offshore structures and foundation's design.

The present themed issue compiles 3 research papers with contributions on the following topics:

- Fatigue and vibration analysis of offshore platforms (Fantuzzi, 2020);

- Design and in situ characterization of subsea gravity-based landers (Gonçalves et al., 2020);

- Marine floating solar platforms (Oliveira-Pinto and Stokkermans, 2020);

Due to the cyclic loading related to marine environment, i.e. wave and wind cyclic loads, offshore structures' design is frequently driven by design restrictions in terms of the fatigue limit state and the associated natural frequency and vibrations. In addition, the effect of extreme sea-state climate (Shao et al., 2020) coupled with fast structural aging in offshore conditions (Fazeres-Ferradosa et al., 2018b; Shen et al., 2020) and marine scour phenomena (Fazeres-Ferradosa et al., 2019c; Liang et al., 2019), contribute for the increased importance of advanced analysis in fatigue and vibration in offshore platforms, for both oil and gas and marine renewable energy.

On the topic of structural design, with a particular focus on their dynamic behaviour, Fantuzzi et al. (2020) present novel research on the topic of smart tuned liquid column dampers to reduce the vibrations in offshore structures. In this paper, the dynamic behaviour of offshore structures modelled as discrete dynamic systems with the installation of innovative smart
Tuned Liquid Column Dampers (TLCDs) with the use of advanced nano-fluids to enhance the dampers mechanical properties. The magnetic force is modelled as an additional non-linear stiffness applied on the main structure once the magnetic field is activated. This paper is a breakthrough contribution to the field that brings novel perspectives on the use of smart TLCDs in comparison to conventional TLCDs systems.

Another interesting topic of offshore structures and foundations is the design and site behaviour of subsea structures. While the majority of the studies reported in the literature concern to pipelines and oil rigs (e.g. Pavlou and Correia, 2019), not many studies are available for other complex structures and geometries. Such type of structures often present numerous challenging design aspects, since not only the structure or foundation has to comply with typical regulations and standards for wave-current induced loads, but also due to their exposure to important phenomena such as scour, differential settlements or the increasing drag forces due to marine growth. In this themed issue, Gonçalves et al. (2020) present a unique study of design optimisation and in situ characterization of the subsea Amalia lander. Amalia lander is a modular gravity-based structure suitable for offshore monitoring, surveillance, damage assessment at offshore foundations, validation of coating in subsea conditions, among several other maritime operations. In addition to its exceptionally complex geometry, the Amalia lander is also built with eco-friendly material Polyoxymethylene, a high-performance thermoplastic of reduced price, low density and high stiffness, that is inert under subsea conditions. The full-scale model is numerically modelled, and the materials' characterization is made for real in situ conditions at the Berlenga Grand Island. The results from Gonçalves et al. (2019) show that design optimisation was achieved for the interface of the rod and the ballast weight and the bearing connection between the cage and the sphere fork, thus highlighting the importance of optimised design as a key aspect for improved performance of complex subsea structures.

Marine Renewable Energy stands as a key drive of the offshore engineering practice and industry. The marine energy developments related to commercial offshore wind and ongoing research related to wave and tidal energy, among other sources, have been representing an important component of the latest research breakthroughs in maritime engineering. The consistent growth in marine energy sector, extensively presented in Taveira-Pinto et al. (2015) and Taveira-Pinto et al. (2020), leads to considerable progress in the development of novel structures and harvesting technologies for renewable energy exploitation. A rising field of research is the development of floating renewable energy farms for offshore locations (Oliveira-Pinto et al., 2019). While floating solar technology 
emerged nearly a decade ago, its application has been mainly restricted to inland freshwater applications, e.g. at dams' reservoirs and similar locations.

State-of-the-art developments have now looked on how to extend such applications to offshore locations, including the exploitation of synergies with other structures, e.g. the use of floating solar systems to provide electricity to offshore oil and gas platforms. In Oliveira-Pinto and Stokermanns (2020), a review is presented on the potential challenges and feasibility of marine floating solar plants. A broad overview of the technology and existing applications is provided with a focus on the possibility of scale-up from nearshore to offshore sites. Furthermore, the risks and challenges of designing and building floating solar systems in marine environment are addressed within a practical perspective. This paper highlights the attractiveness of this technology as a potential way to explore the vast energy resources that lie at offshore sites. OliveiraPinto and Stokkermans (2020) work closes this themed issue that is, indeed, a broad issue covering a wide spectrum of advanced research matters related to offshore structures and foundation's design in both parts 1 and 2 .

\section{Conclusions}

Each structure and foundation placed at sea is a landmark of engineers' ambition and boldness towards the exploitation of the vast offshore resources that Earth offers to Mankind. However, the design of offshore structures and foundations is filled with complex problems, which require advanced research for the implementation of proper and practical solutions.

In addition, the research on existing knowledge gaps is a crucial requirement to increase the sector's competitiveness and to reduce its exposure and volatile behaviour related to natural hazards, geopolitical events and other globalised crises.

In this sense, the present themed issue provides ground-breaking contributions to state-of-the-art research related to the topic of offshore structures and foundation design. The current issue is an appealing set of research and practical case papers for professionals and academy members dealing with offshore engineering, with a focus on maters that relate to maritime, civil and mechanical engineering, among other fields of activity.

\section{Acknowledgments}

The International Offshore Structures Design course team acknowledges the kindness of Maritime Engineering editorial team in the support of the present themed issue. A deep acknowledgment is made to John Harris (HR Wallingford) for his prompt acceptance of the themed issue proposal (Part 1 and 2) and support throughout the editorial activities. Craig Schaper and Hassan Akhtar are also acknowledged for the crucial help during the editorial, production and publishing stages of this issue. Finally, the IOSD organisers Prof. TaveiraPinto, Prof. Rosa-Santos and Dr. Fazeres-Ferradosa kindly appreciate the lecturers, reviewers, authors and supporting institutions that contributed to the organisation of the course and the quality of this themed issue. FEUP team was supported by the project POCI-01-0145-FEDER-032170 (ORACLE project), funded by the European Fund for Regional Development (FEDER), through the COMPETE2020, the Programa Operacional Competitividade e Internacionalização (POCI) and FCT/MCTES through national funds (PIDDAC).

\section{REFERENCES}

Correia JAFO, Ferradosa T, Castro JM, Fantuzzi N and Jesus AMPD (2019) Editorial: Renewable energy and oceanic structures: Part i. Proceedings of the Institution of Civil Engineers: Maritime Engineering 172(1): 1-2. doi: 10.1680/jmaen.2019.172.1.1.

East M (2018) Design for accessibility for floating structures. Proceedings of the Institution of Civil Engineers: Maritime Engineering 171(3): 98-108. doi: 10.1680/jmaen.2018.12.

Edesess AJ, Kelliher D, Borthwick AGL and Thomas GP (2017) Offshore monopile in the southern North Sea: Part I, calibrated input sea state. Proceedings of the Institution of Civil Engineers: Maritime Engineering 170(3-4): 122-132. doi: 10.1680/ jmaen.2017.14.

Edesess AJ, Kelliher D and Borthwick AGL (2018) Offshore monopile in the southern North Sea: Part II, simulated hydrodynamics and loading. Proceedings of the Institution of Civil Engineers: Maritime Engineering 171(2): 70-85. doi: 10.1680/jmaen.2018.16.

Fantuzzi N (2020) Smart tuned liquid column damper for reducing structural vibrations in offshore structures. Proceedings of the Institution of Civil Engineers: Maritime Engineering 173(4): 100-109, https://doi.org/10.1680/jmaen.2019.18.

Fazeres-Ferradosa T, Taveira-Pinto F, Reis MT and Das Neves L (2018a) Physical modelling of dynamic scour protections: Analysis of the damage number. Proceedings of the Institution of Civil Engineers: Maritime Engineering 171(1): 11-24. doi: 10.1680/ jmaen.2017.26.

Fazeres-Ferradosa T, Taveira-Pinto F, Vanem E, Reis MT and Neves LD (2018b) Asymmetric copula-based distribution models for metocean data in offshore wind engineering applications. Wind Engineering 42(4): 304-334. doi: 10.1177/0309524X18777323.

Fazeres-Ferradosa T, Rosa-Santos P, Taveira-Pinto F et al. (2019) Editorial: Advanced research on offshore structures and foundation design: Part 1. Proceedings of the Institution of Civil Engineers: Maritime Engineering 172(4): 118-123. doi: 10.1680/jmaen.2019.172.4.118.

Fazeres-Ferradosa T, Taveira-Pinto F, Rosa-Santos P and Chambel J (2019b) A review of reliability analysis of offshore scour protections. Proceedings of the Institution of Civil Engineers: Maritime Engineering 172(3): 104-117. doi: 10.1680/jmaen.2019.11.

Fazeres-Ferradosa T, Taveira-Pinto F, Rosa-Santos P and Chambel J (2019c) Probabilistic comparison of static and dynamic failure criteria of scour protections. Journal of Marine Science and Engineering 7(11): doi: 10.3390/jmse7110400.

Gonçalves AF, Gomes O, Mathias N, Morais T and Ferradosa T (2020) Numerical modelling of full-scale subsea lander Amalia with in situ conditions. Proceedings of the Institution of Civil Engineers: Maritime Engineering 173(4): 110-119, https://doi.org/10.1680/ jmaen.2019.29. 
Hames D, Gouldby B and Hawkes P (2019) Evolution of joint probability methods in coastal engineering practice in the UK. Proceedings of the Institution of Civil Engineers: Maritime Engineering. 172(2): 45-54, https://doi.org/10.1680/jmaen.2019.4.

Jiang B, Wu G, Ding J et al. (2019) Assessment of the wave energy resource in the South China Sea. Proceedings of the Institution of Civil Engineers: Maritime Engineering 172(1): 23-33. doi: 10.1680/jmaen.2018.29.

Liang B, Du S, Pan X and Zhang L (2020) Local Scour for Vertical Piles in Steady Currents: Review of Mechanisms, Influencing Factors and Empirical Equations. Journal of Marine Science and Engineering 8(1): 4, https://doi.org/10.3390/jmse8010004.

Mourão A, Correia J, Ávila B et al. (2020) A fatigue damage evaluation using local damage parameters for an offshore structure. Ahead of Print 1-35, https://doi.org/10.1680/jmaen.2019.24.

Oliveira-Pinto S, Rosa-Santos P and Taveira-Pinto F (2019) Electricity supply to offshore oil and gas platforms from renewable ocean wave energy: Overview and case study analysis. Energy Conversion and Management 186: 556-569. doi: 10.1016/j. enconman.2019.02.050.

Oliveira-Pinto S and Stokkermans J (2020) Marine Floating Solar Plants: An overview of potential, challenges and feasibility. Proceedings of the Institution of Civil Engineers: Maritime Engineering 173(4): 120-135, https://doi.org/10.1680/jmaen.2020.10.

Pavlou D (2019) Curved fibre-reinforced-polymer risers: inner flow-induced dynamic instability analysis. Proceedings of the Institution of Civil Engineers: Maritime Engineering 172(4): 133-147, https://doi.org/10.1680/jmaen.2019.16.
Pavlou DG and Correia JA (2019) Dynamic response of pipelines under impact and harmonic loading. Proceedings of the Institution of Civil Engineers: Maritime Engineering 172(1): 15-22. doi: 10.1680/jmaen.2019.2.

Shao Z, Liang B and Gao H (2020) Extracting independent and identically distributed samples from time series significant wave heights in the Yellow Sea. Coastal Engineering 158, https://doi. org/10.1016/j.coastaleng.2020.103693.

Shen J, Liu F, Li H, Xu L and Liang B (2015) Assessment of the damages occurring between two adjacent measurements for an aging offshore platform. Ocean Engineering 109: 372-380, https:// doi.org/10.1016/j.oceaneng.2015.09.024.

Strachan R (2020) 28th of April. Covid-19 creates supply and demand crisis for oil and gas. Offshore Technology. Retrieved in 18th of May 2020 from: https://www.offshore-technology.com/investment/ covid-19-creates-supply-and-demand-crisis-for-oil-and-gas/.

Taveira-Pinto F, Iglesias G, Rosa-Santos P and Deng ZD (2015) Preface to Special Topic: Marine Renewable Energy Journal of Renewable and Sustainable Energy 7(6): 061601. https://doi.org/10.1063/ 1.4939086.

Taveira-Pinto F, Rosa-Santos P and Fazeres-Ferradosa T (2020) Marine renewable energy. Renewable Energy 150: 1160-1164. doi: 10.1016/j.renene.2019.10.014.

Vanem E, Fazeres-Ferradosa T, Rosa-Santos P and Taveira-Pinto F (2019) Statistical description and modelling of extreme ocean wave conditions. Proceedings of the Institution of Civil Engineers: Maritime Engineering 172(4): 124-132. doi: 10.1680/jmaen.2019.20. 